Article

\title{
Synthesis of 5-Substituted 3-Amino-1H-Pyrazole-4-Carbonitriles as Precursors for Microwave Assisted Regiospecific Syntheses of Pyrazolo[1,5-a]Pyrimidines
}

\author{
Fawzia Al-Qalaf ${ }^{1}$, Faisal Mandani ${ }^{2}$, Mervat Mohammed Abdelkhalik ${ }^{1, *}$ and Abeer \\ Abdulrahman Bassam ${ }^{1}$
}

1 Applied Science Department, College of Technological Studies, Public Authority for Applied Education and Training, P. O. Box 42325 Safat, 70654 Kuwait; E-mail: manalabbas@hotmail.com (F. A-O.), sweetheart.2006@hotmail.com (A-A. B.)

2 Chemical Engineering Technology Department, College of Technological Studies, Public Authority for Applied Education and Training, P. O. Box 42325 Safat, 70654 Kuwait

* Author to whom correspondence should be addressed; E-mail: mervatak@yahoo.com.

Received: 23 November 2008; in revised form: 15 December 2008 / Accepted: 17 December 2008 / Published: 29 December 2008

\begin{abstract}
A simple route to 3-oxoalkanonitrile 5, a precursor of the title compounds is described. Reaction of enaminones 2 with hydroxylamine hydrochloride in ethanol yielded aldoximes 3 that were converted readily into 5 in basic medium. This method has been successfully applied with a number of substrates and resulted in excellent yields of the products. Reacting 5 with trichloroacetonitrile afforded 3-amino-2-aroyl-4,4,4trichloro-2-butenenitriles 6 that condensed with hydrazines to yield 3-amino- $1 \mathrm{H}$ pyrazole-4-carbonitrile derivatives 8. Substituted pyrazolo[1,5-a]pyridmidines have been prepared with regioselective condensation reactions of $\mathbf{8}$ with nonsymmetrical dielectrophiles. The structures of compounds obtained were deduced based on ${ }^{1} \mathrm{H}-\mathrm{NMR}$, ${ }^{1} \mathrm{H}_{-}{ }^{15} \mathrm{~N}$ HMBC- measurements.
\end{abstract}

Keywords: Oxoalkanonitriles; 2-Aroyl-3-dimethylamino-2-propenenitrile; Pyrazolo[1,5a]pyrimidines; Solvent-free reactions; ${ }^{1} \mathrm{H}^{-15} \mathrm{~N}$ HMBC. 


\section{Introduction}

Interest in pyrazolo[1,5-a]pyrimidine-3-carbonitrile derivatives has been reviewed [1-3]. Among them are zaleplon (1, Figure 1) analogues, that have been classified as sedative/hypnotic drugs, and as such, are expected to possess considerable biological activity [4-6]. With the aim of obtaining compounds possessing the above properties, we examined the condensation of 5-substituted 3-amino1H-4-pyrazolecarbonitriles 8 with bidentate electrophiles and investigated if such compounds would facilitate regioselective syntheses of substituted 7-aryl-pyrazolo[1,5-a]pyrimidine-3-carbonitriles that are structurally related to compound $\mathbf{1}$. Compound $\mathbf{8 a}$ is readily available from the reaction of 3-oxo-3phenylpropanenitrile 5a with trichloroacetonitrile followed by condensation with hydrazine hydrate [7]. This methodology was extended and adapted to the synthesis of several 5-substituted aryl and heteroaryl-pyrazolecarbonitriles using oxoalkanonitriles as precursors. We initially investigated developing a novel route to 3-oxoalkanonitrile derivatives 5 .

Figure 1. Zaleplon.

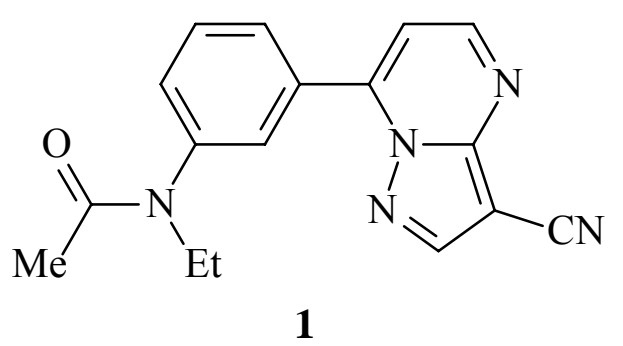

\section{Results and Discussion}

Recently we reported that the reaction of enaminones 2 with hydroxylamine hydrochloride gave the aldoximes $\mathbf{3}$ in good yields. These were converted to oxoalkanonitriles $\mathbf{5}$ via treatment with diethyl oxalate in the presence of sodium hydride [8]. We now describe a second more efficient process for the preparation of $\mathbf{5}$ by addition of a solution of hydroxylamine hydrochloride to enaminones 2a-c in alcoholic $\mathrm{KOH}$. Such a transformation apparently results via initial formation of an isoxazole 4 that then undergoes base catalyzed ring opening furnishing 5a-c (cf. Scheme 1).

Scheme 1. Synthesis of 3-oxo-3-arylpropanenitriles 5a-c from enaminones 2a-c.<smiles>[R]C(=O)/C=C/N(C)C</smiles>

2<smiles>[R]C(=O)CC=NO</smiles>

3

$$
\begin{aligned}
\text { 2-5a, } \mathrm{R} & =\mathrm{C}_{6} \mathrm{H}_{5} \\
\mathbf{b}, \mathrm{R} & =4-\mathrm{ClC}_{6} \mathrm{H}_{4} \\
\text { c, } \mathrm{R} & =2-\text { Thienyl }
\end{aligned}
$$<smiles>[R]C(=O)CC#N</smiles><smiles>[R]c1ccno1</smiles> 
The oxoalkanonitrile derivatives 5a-c so obtained were reacted with trichloroacetonitrile to yield adducts 6a-c. Condensation of these adducts with hydrazine hydrate afforded 7a-c, that cyclized under reflux in dioxane yielding 8a-c in good yields (cf. Scheme 2). The doublet splitting of amino group signals observed in the ${ }^{1} \mathrm{H}-\mathrm{NMR}$ spectra of adducts $\mathbf{6 a - c}$ at ca. $\delta_{\mathrm{H}}=10$ and $12 \mathrm{ppm}$ indicates a nonequivalence of the amino protons, which is probably related to the involvement of one amino proton in an intramolecular H-bond with the carbonyl moiety. Similar features were observed in $\mathbf{7 a - c}$ at ca. $\delta_{\mathrm{H}}=$ 9 and $10 \mathrm{ppm}$. There are alternative procedures described in the literature for the preparation of 8a,b by treating arylmethylenemalononitrile with hydrazine $[9,10]$ or via transformation of isothiazoles and isoxazoles into pyrazoles 8a,b using hydrazines [11]. In the present article, the condensation reaction of 3-amino-1H-4-pyrazolecarbonitrile derivatives 8a-c with enaminone 2c and enaminonitrile 9, recently prepared in our laboratory [12], is examined.

Scheme 2. Synthesis of 3-amino-5-aryl-1H-4-pyrazolecarbonitrile 8a-c from 3-oxo-3arylpropanenitrile 5a-c.

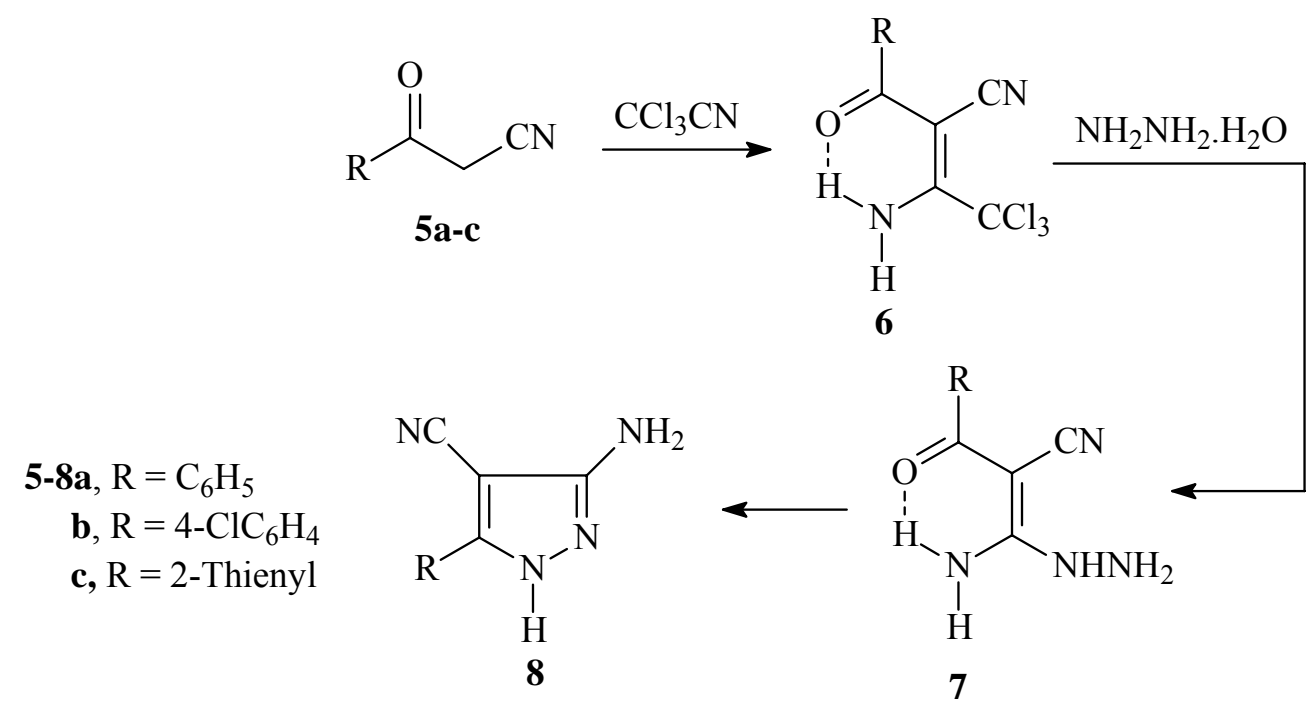

The site at which nucleophiles attack occurs on $1 \mathrm{H}$-3-aminopyrazole derivatives has been a subject of considerable debate in the past [13-14]. Reactions of unsymmetrical 1,3-diketones with 3(5)aminopyrazoles often lead to the formation of inseparable mixtures of two regioisomeric pyrazolo[1,5a]pyrimidines due to comparable reactivity's of the two electrophilic centers in the initial diketone. Recently, use of 1,3-dimethyluracil as the electrophile was reported to involve the attack on both endocyclic and exocyclic nitrogen affording either the pyrazolo[1,5-a]pyrimidin-5-one or 7-one isomers, depending on the reaction conditions [15], whereas the reaction of $1 \mathrm{H}$-3-aminopyrazole with benzylidenemalononitrile [16] and with 1-arylbutane-1,3-diones [17] are established to involve exocyclic amino group. It is thought that there is an equilibrium between possible initial attack at the ring nitrogen and the exocyclic amino group. Structures of the products resulting from reactions of $\alpha, \beta$-unsaturated compounds with aminoazoles should be determined in each case, as the outcome of the reactions would be dependent on several factors, including steric consideration, relative basicities and solubility of both isomers in reaction medium. Although it is generally accepted that 3(5)aminopyrazoles reacts with enaminones to yield the 7-substituted isomers, we noticed that this pattern is not always followed, as the reaction product proved to be dependent on both reaction conditions as 
well as nature of reagents. In the present article we have found that reaction of 8a-c with enaminonitrile 2c in acetic acid at reflux temperature over a long period of time resulted in selective formation of pyrazolo[1,5-a]pyrimidines derivatives in good yields (cf. Scheme 3).

Scheme 3. Proposed mechanism for the formation of pyrazolo[1,5-a]pyrimidines 12a-c, 13a-c and 15a-c in acetic acid.

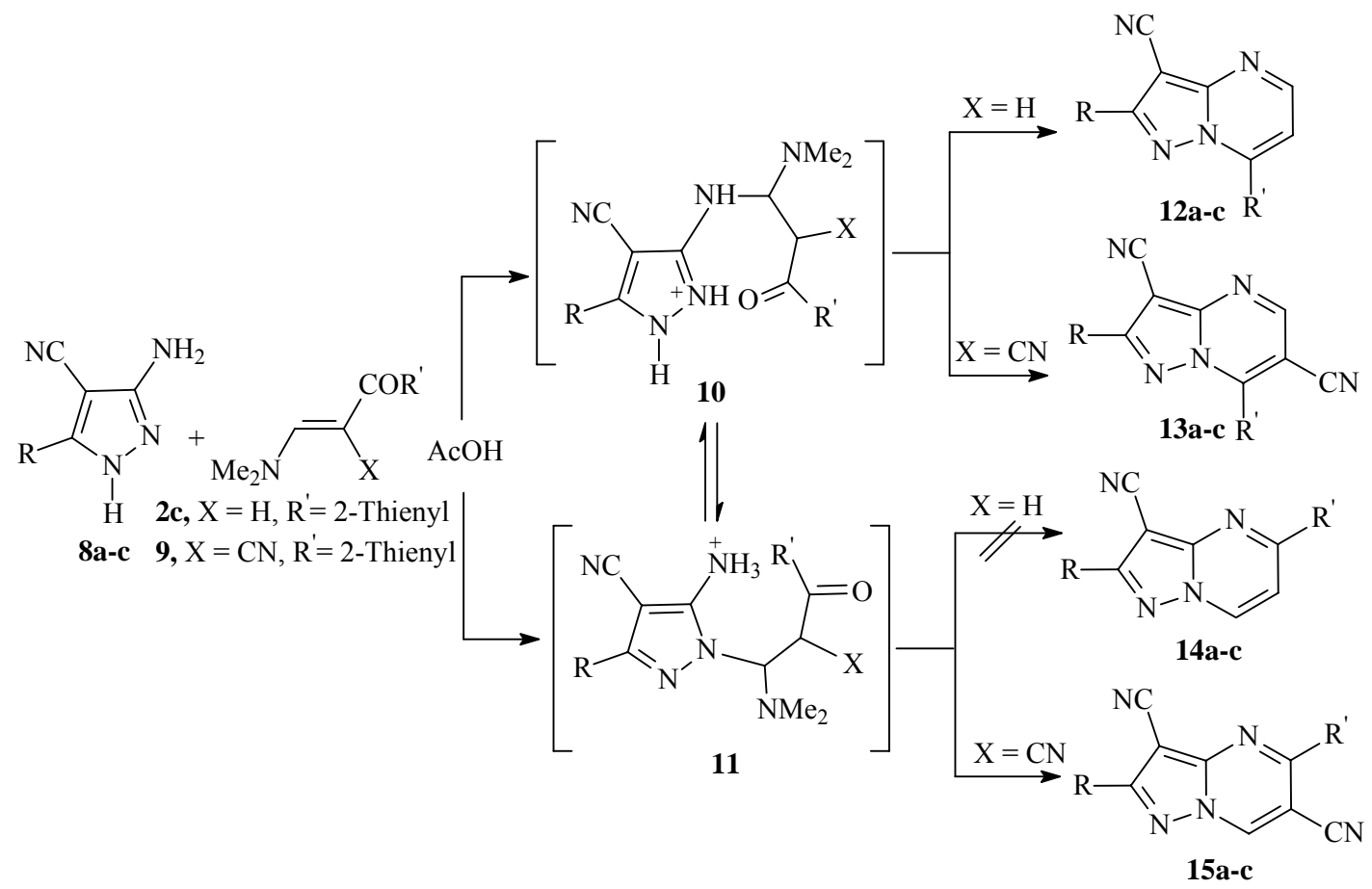

The ${ }^{1} \mathrm{H}-\mathrm{NMR}$ spectra gave no reliable information on the structure of the products; on the other hand they indicate that only one of the possible isomeric structures, 12 or 14, are formed, rather than their mixture. The condensation products were assigned structures $12 \mathrm{a}-\mathbf{c}$ on the basis of ${ }^{1} \mathrm{H}-{ }^{15} \mathrm{~N} \mathrm{HMBC}$ measurements. For example compound 12a, showed chemical shifts for N-7a at $\delta\left({ }^{15} \mathrm{~N}\right)=215 \mathrm{ppm}, \mathrm{N}-$ 4 at $\delta\left({ }^{15} \mathrm{~N}\right)=268 \mathrm{ppm}$. and $\mathrm{N}-1$ at $\delta\left({ }^{15} \mathrm{~N}\right)=285 \mathrm{ppm}$. Cross peak correlations for the coupling of the shielded proton $\mathrm{H}-6$ at $\delta\left({ }^{1} \mathrm{H}\right)=8.05 \mathrm{ppm}$ is observed with $\mathrm{N}-7 \mathrm{a}$ at $\delta\left({ }^{15} \mathrm{~N}\right)=215 \mathrm{ppm}{ }^{3} \mathrm{~J}(\mathrm{H}-6, \mathrm{~N}-7 \mathrm{a})$, $\mathrm{N}-4$ at $\delta\left({ }^{15} \mathrm{~N}\right)=268 \mathrm{ppm}{ }^{3} J(\mathrm{H}-6, \mathrm{~N}-4)$ and with $\mathrm{N}-1$ at $\delta\left({ }^{15} \mathrm{~N}\right)=285 \mathrm{ppm}{ }^{4} J(\mathrm{H}-6, \mathrm{~N}-1)$. Coupling of the deshielded proton at $\delta\left({ }^{1} \mathrm{H}\right)=8.83$ ppm with $\mathrm{N}-7 \mathrm{a}$ at $\delta\left({ }^{15} \mathrm{~N}\right)=215 \mathrm{ppm}{ }^{4} J(\mathrm{H}-5, \mathrm{~N}-7 \mathrm{a})$ and with N4 at $\delta\left({ }^{15} \mathrm{~N}\right)=268 \mathrm{ppm}^{2} J(\mathrm{H}-5, \mathrm{~N}-4)$ are also observed. Alternative structure 14 would show coupling of the deshielded $\mathrm{H}-7$ proton to be with $\mathrm{N}-1$ in the spectrum at $\delta\left({ }^{15} \mathrm{~N}\right)=285 \mathrm{ppm}$. The correlations in the ${ }^{1} \mathrm{H}^{15} \mathrm{~N}$ HMBC measurements for compounds $\mathbf{1 2} \mathbf{b}, \mathbf{c}$ showed similar coupling correlations as 12a. Reaction of 3-amino-5-aryl-1H-4-pyrazolecarbonitriles 8a-c with enaminonitrile $9(\mathrm{X}=\mathrm{CN})$ in acetic acid under the same reaction conditions afforded a mixture of (5)7-substituted pyrazolo[1,5a]pyrimidine derivatives 13a-c and 15a-c, which could not be separated by chromatographical means. Both isomers showed the same molecular weights in LC-MS. Moreover, the ${ }^{1} \mathrm{H}-\mathrm{NMR}$ spectra of the reaction products of 8a-c with 9 showed two singlets for two deshielded protons at ca. $\delta_{\mathrm{H}}=9.0$ and 9.3 ppm. Based on these data, it is concluded that the compounds obtained are isomeric mixtures of 13 and 15, whose ratio (approximately 1:3) was estimated by integration of the deshielded protons in the corresponding ${ }^{1} \mathrm{H}-\mathrm{NMR}$ spectra. Apparently, in $\mathrm{AcOH}$ where the aminopyrazoles are most likely 
protonated, both adducts $\mathbf{1 0}$ and $\mathbf{1 1}$ are formed, as outlined in Scheme 3. Competing cyclization leading to the 5-isomer would also be possible and mixtures are thus formed.

On the other hand, reaction of 3-amino-5-aryl-1H-4-pyrazolecarbonitriles 8a-c with enaminonitrile $9(\mathrm{X}=\mathrm{CN})$ by heating in a direct beam microwave oven and under solvent free conditions proceeded regiospecifically to yield the 5-substituted pyrazolo[1,5-a]pyrimidine-3-carbonitrile derivatives 15a-c in good yield. The addition reaction occurs in a manner different to the formation of the 7-substituted pyrazolo[1,5-a]pyrimidine derivatives, as outlined in Scheme 4. The structure 15 of the products obtained was assigned on the basis of ${ }^{1} \mathrm{H}_{-}{ }^{15} \mathrm{~N}$ HMBC measurements. The major discrepancy between the two isomers 13 and 15 was the cross peak correlation observed between the deshielded proton at $\delta$ $\left({ }^{1} \mathrm{H}\right)=9.06 \mathrm{ppm}$ with $\mathrm{N}-1$ at $\delta\left({ }^{15} \mathrm{~N}\right)=283 \mathrm{ppm},{ }^{3} \mathrm{~J}(\mathrm{H}-7, \mathrm{~N}-1)$. Alternate structure 13 in which the deshielded proton is on C-5, would not show this correlation and thus structure $\mathbf{1 3}$ could be ruled out. There is no doubt that adducts at both exocyclic and endocyclic nitrogen atoms occur, but in this case, the latter cyclize more readily into the 5-substituted pyrazolo[1,5-a]pyrimidines derivatives thus shifting the equilibrium. It should be noted that the isomers 12a-c were also obtained as sole products when the reactions of 8a-c with $\mathbf{2 c}$ was carried out by heating in a direct beam microwave oven and under solvent free conditions.

Scheme 4. Cyclocondensation reaction of 8a-c with 2c and 9 by heating in a direct beam microwave oven and solvent free conditions resulted in selective formation of pyrazolo[1,5-a]pyrimidines 12a-c and 15a-c.

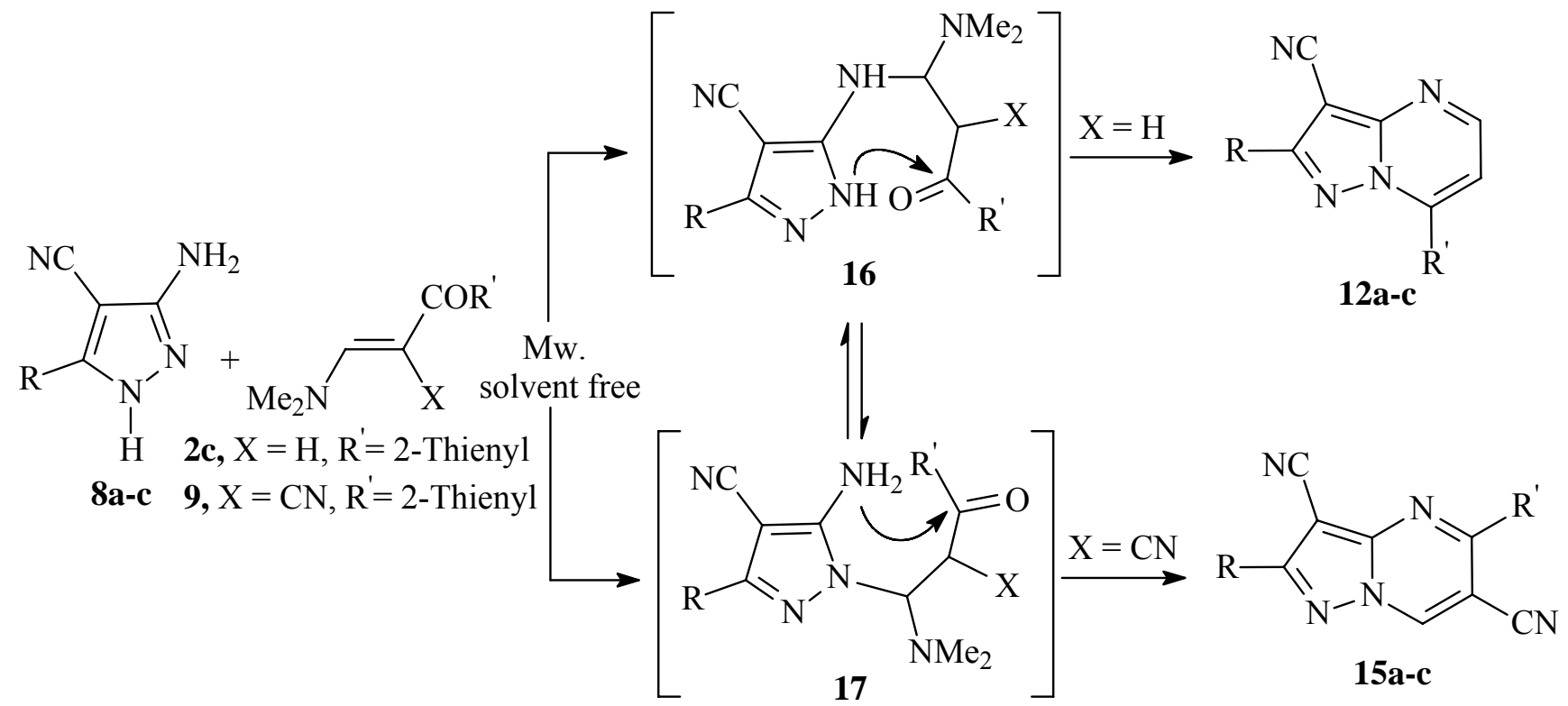

The behavior of 8a-c with 9 under microwave irradiation may be attributed to the formation of hot spots that affect the reaction selectivity due to the increase in heating rate. This may lead to the formation of thermodynamically stable products in preference to the kinetic ones $[18,19]$. One can thus conclude that this solvent-free reactions proceeds in a regiospecific fashion by the relative reactivity of exocyclic nitrogen and ring nitrogen atoms. 


\section{Experimental}

\section{General}

Melting points were determined on a Shimadzu-Gallenkamp apparatus and are uncorrected. Microwave mediated chemistry was conducted in heavy-walled Pyrex tubes fitted with PCS cap. and performed with a single mode cavity Explorer Microwave Synthesizer (CEM Corporation, NC, USA), producing continuous irradiation and equipped with simultaneous external air-cooling system. Elemental analyses were obtained on a LECO CHNS-932 Elemental Analyzer. ${ }^{1} \mathrm{H}-\mathrm{NMR}$ spectra were obtained in DMSO- $d_{6}$ on a Bruker DPX $400 \mathrm{MHz}$ superconducting spectrometer in DMSO- $\mathrm{d}_{6}$ with TMS as an internal standard. Two-dimensional NMR spectra were determined on Bruker Avance II $600 \mathrm{MHz}$ superconducting spectrometer in DMSO- $\mathrm{d}_{6}$ and FT-IR measurements were recorded in $\mathrm{KBr}$ disks on a Perkin Elmer 2000 FT-IR system. Mass spectrometric analyses were recorded on a VGAutospec-Q high performance tri-sector GC/MS/MS.

\section{General procedure for the preparation of compounds 5a-c}

A mixture of each enaminone 2a-c $(10 \mathrm{mmol})$ and $\mathrm{NH}_{2} \mathrm{OH} . \mathrm{HCl}(0.69 \mathrm{~g}, 10 \mathrm{mmol})$ in EtOH $(30$ $\mathrm{mL})$, was added a solution of $\mathrm{KOH}(5.60 \mathrm{~g}, 10 \mathrm{mmol})$ in $\mathrm{H}_{2} \mathrm{O}(8 \mathrm{~mL})$. The reaction mixture was heated under reflux and deemed completed when the yellow color of the solution changed to brown (in 30-60 min.). The reaction mixtures were then poured onto water and neutralized with $\mathrm{HCl}$. The solid products so obtained were collected by filtration and crystallized from benzene.

3-Oxo-3-phenylpropanenitrile (5a): White crystals, yield (89 \%, $1.30 \mathrm{~g})$; mp 79-81 ${ }^{\circ} \mathrm{C}$ (Lit. [12-13] mp. 80-82); IR $\left(\mathrm{cm}^{-1}\right): 2255(\mathrm{CN})$ and $1689(\mathrm{CO}) ; \mathrm{MS} \mathrm{m} / \mathrm{z}(\mathrm{M})^{+}=145 ;{ }^{1} \mathrm{H}-\mathrm{NMR}: \delta=4.78(\mathrm{~s}, 2 \mathrm{H}$, $\mathrm{CH}_{2}$ ), 7.57 (t, 2H, $\left.J=6.8 \mathrm{~Hz}, \mathrm{Ph}-\mathrm{H}\right), 7.72$ (t, 1H, J=7.4 Hz, Ph-H), 7.94 (d, 2H, J=6.8 Hz, Ph-H); Anal. calcd. for $\mathrm{C}_{9} \mathrm{H}_{7} \mathrm{NO}$ : (145.16): C, 74.47; H, 4.86; N, 9.65. Found: C, 74.50; H, 4.75; N, 9.57.

3-(4-Chlorophenyl)-3-oxopropanenitrile (5b): Yellow crystals, yield (86 \%, $1.54 \mathrm{~g})$; mp 126-128 ${ }^{\circ} \mathrm{C}$ (Lit. [12-13] mp. $\left.128{ }^{\circ} \mathrm{C}\right)$; IR $\left(\mathrm{cm}^{-1}\right): 2255(\mathrm{CN})$ and $1680(\mathrm{CO}) ; \mathrm{MS} \mathrm{m} / \mathrm{z}(\mathrm{M})^{+}=179 ;{ }^{1} \mathrm{H}-\mathrm{NMR}: \delta=$ $4.75\left(\mathrm{~s}, 2 \mathrm{H}, \mathrm{CH}_{2}\right), 7.60(\mathrm{~d}, 2 \mathrm{H}, J=8.1 \mathrm{~Hz}$, arom-H), $7.75(\mathrm{~d}, 2 \mathrm{H}, J=8.3 \mathrm{~Hz}$, arom-H); Anal. calcd. for $\mathrm{C}_{9} \mathrm{H}_{6} \mathrm{ClNO}$ (179.01): C, 60.19; H, 3.37; N, 7.80. Found: C, 59.87; H, 3.30; N, 7.67.

3-Oxo-3-(2-thienyl)propanenitrile 5c: Yellow crystals, yield (88 \%, $1.32 \mathrm{~g})$; mp 112-114 ${ }^{\circ} \mathrm{C}$ (Lit. [1213] mp. 110-112 $\left.{ }^{\circ} \mathrm{C}\right)$; IR $\left(\mathrm{cm}^{-1}\right)$ : $3243\left(\mathrm{NH}_{2}\right), 2255(\mathrm{CN})$ and $1666(\mathrm{CO}) ; \mathrm{MS} \mathrm{m} / \mathrm{z}(\mathrm{M})^{+}=151 ;{ }^{1} \mathrm{H}_{-}$ NMR: $\delta=4.72\left(\mathrm{~s}, 2 \mathrm{H}, \mathrm{CH}_{2}\right), 7.30(\mathrm{t}, 1 \mathrm{H}, J=4.4 \mathrm{~Hz}$, thienyl H-4), $7.99(\mathrm{~d}, 1 \mathrm{H}, J=4.8 \mathrm{~Hz}$, thienyl H3), 8.14 (d, $1 \mathrm{H}, J=4.8 \mathrm{~Hz}$, thienyl H-5); Anal. calcd. for $\mathrm{C}_{7} \mathrm{H}_{5} \mathrm{NOS}$ : (151.19): C, 55.61; H, 3.33; N, 9.26; S, 21.21. Found: C, 55.72; H, 3.31; N, 9.28; S, 21.00. 


\section{General procedure for the preparation of compounds 6a-c}

To a stirred mixture of each of oxoalkanonitrile 5a-c $(10 \mathrm{mmol})$ in EtOH $(20 \mathrm{~mL})$ and in the presence of anhydrous NaOAc $(1 \mathrm{~g})$, was added 3,3,3-trichloropropanenitrile (10 mmol, $1.57 \mathrm{~g})$. The resulting mixture was stirred for six hrs at r.t., then evaporated under vacuum to half its volume. The reaction mixture was then poured onto water. The solid product obtained was collected by filtration and crystallized from ethanol.

(Z)-3-Amino-2-benzoyl-4,4,4-trichloro-2-butenenitrile (6a): Pale yellow crystals, yield (82 \%, $2.36 \mathrm{~g})$; mp 182-184 ${ }^{\circ} \mathrm{C}$; IR $\left(\mathrm{cm}^{-1}\right)$ : 3267 and $3250\left(\mathrm{NH}_{2}\right), 2210(\mathrm{CN})$ and $1613(\mathrm{CO}) ; \mathrm{MS} \mathrm{m} / \mathrm{z}\left(\mathrm{M}^{+}-1\right)=288$; ${ }^{1} \mathrm{H}-\mathrm{NMR}: \delta=7.48$ (t, 2H, $\left.J=7.8 \mathrm{~Hz}, \mathrm{Ph}-\mathrm{H}\right), 7.57$ (t, $\left.1 \mathrm{H}, J=7.9 \mathrm{~Hz}, \mathrm{Ph}-\mathrm{H}\right), 7.68$ (d, 2H, J = 7.8 Hz, $\mathrm{Ph}-\mathrm{H}), 9.96\left(\mathrm{~s}, 1 \mathrm{H}, \mathrm{NH}_{2}\right), 11.94\left(\mathrm{~s}, 1 \mathrm{H}, \mathrm{NH}_{2}\right)$; Anal. calcd. for $\mathrm{C}_{11} \mathrm{H}_{7} \mathrm{Cl}_{3} \mathrm{~N}_{2} \mathrm{O}$ : (289.55): C, 45.63; $\mathrm{H}$, 2.44; N, 9.67. Found: C, 45.90; H, 2.41; N, 9.56.

(Z)-3-Amino-4,4,4-trichloro-2-(4-chlorobenzoyl)-2-butenenitrile (6b): Yellow crystals, yield (76 \%, $2.46 \mathrm{~g})$; mp 221-222 ${ }^{\circ} \mathrm{C}$; IR ( $\left.\mathrm{cm}^{-1}\right): 3260\left(\mathrm{NH}_{2}\right), 2214(\mathrm{CN})$ and $1610(\mathrm{CO}) ; \mathrm{MS} \mathrm{m} / \mathrm{z}\left(\mathrm{M}^{+}-1\right)=322 ;{ }^{1} \mathrm{H}-$ NMR: $\delta=7.58\left(\mathrm{~d}, 2 \mathrm{H}, J=8.0 \mathrm{~Hz}\right.$, arom-H), $7.71\left(\mathrm{~d}, 2 \mathrm{H}, J=8.2 \mathrm{~Hz}\right.$, arom-H), $10.05\left(\mathrm{~s}, 1 \mathrm{H}, \mathrm{NH}_{2}\right)$, 11.87 (s, $1 \mathrm{H}, \mathrm{NH}_{2}$ ); Anal. calcd. for $\mathrm{C}_{11} \mathrm{H}_{6} \mathrm{Cl}_{4} \mathrm{~N}_{2} \mathrm{O}$ : (323.99): C, 40.78; H, 1.87; N, 8.65. Found: C, $40.90 ; \mathrm{H}, 2.02 ; \mathrm{N}, 8.80$.

(Z)-3-Amino-4,4,4-trichloro-2-(thiophene-2-carbonyl)-2-butenenitrile (6c): Brown crystals, yield (85 \%, $2.50 \mathrm{~g})$; $\mathrm{mp} 168-170{ }^{\circ} \mathrm{C}$; IR $\left(\mathrm{cm}^{-1}\right)$ : $3243\left(\mathrm{NH}_{2}\right), 2216(\mathrm{CN})$ and $1624(\mathrm{CO}) ; \mathrm{MS} \mathrm{m} / \mathrm{z}\left(\mathrm{M}^{+}-1\right)=294$; ${ }^{1} \mathrm{H}-\mathrm{NMR}: \delta=7.25(\mathrm{t}, 1 \mathrm{H}, J=4.0 \mathrm{~Hz}$, thienyl H-4), $8.01(\mathrm{~d}, 1 \mathrm{H}, J=5.2 \mathrm{~Hz}$, thienyl H-3), $8.17(\mathrm{~d}, 1 \mathrm{H}, J$ $=4.0 \mathrm{~Hz}$, thienyl $\mathrm{H}-5), 9.96\left(\mathrm{~s}, 1 \mathrm{H}, \mathrm{NH}_{2}\right), 12.01\left(\mathrm{~s}, 1 \mathrm{H}, \mathrm{NH}_{2}\right)$; Anal. calcd. for $\mathrm{C}_{9} \mathrm{H}_{5} \mathrm{Cl}_{3} \mathrm{~N}_{2} \mathrm{OS}$ : (295.57): C, 36.57; H, 1.71; N, 9.48; S, 10.85. Found: C, 36.25; H, 1.96; N, 9.25; S, 10.50.

Reaction of 6a-c with hydrazine hydrate for the preparation of 7a-c

To each compound 6a-c $(10 \mathrm{mmol})$, excess hydrazine hydrate $(3 \mathrm{~mL})$ was added and stirred for 3 min. (exothermic reaction). The reaction mixture is then allowed to cool to ambient temperature. During time a precipitate is formed that was filtered off and recrystallized from ethanol.

(E)-3-Amino-2-benzoyl-3-hydrazino-2-propenenitrile (7a): This compound was obtained as white crystals, yield (93\%, $1.90 \mathrm{~g})$; mp 143-145 ${ }^{\circ} \mathrm{C}$; IR $\left(\mathrm{cm}^{-1}\right): 3444,3345$ and $3209\left(\mathrm{NH}\right.$ and $\left.\mathrm{NH}_{2}\right), 2182$ $(\mathrm{CN})$ and $1656(\mathrm{CO})$; MS m/z $(\mathrm{M})^{+}=202 ;{ }^{1} \mathrm{H}-\mathrm{NMR}: \delta=4.72\left(\mathrm{~s}, 2 \mathrm{H}, \mathrm{NH}_{2}\right), 7.38-7.46(\mathrm{~m}, 3 \mathrm{H}$, arom. H), 7.48 (br s, 1H, NH), 7.58 (d, 2H, J = 7.8 Hz, arom-H), 8.51 (s, 1H, $\left.\mathrm{NH}_{2}\right), 9.69$ (s, 1H, $\mathrm{NH}_{2}$ ); Anal. calcd. for $\mathrm{C}_{10} \mathrm{H}_{10} \mathrm{~N}_{4} \mathrm{O}$ : (202.21): C, 59.40; H, 4.98; N, 27.71. Found: C, 59.36; H, 5.2; N, 27.95.

(E)-3-Amino-2-(4-chlorobenzoyl)- 3-hydrazino-2-propenenitrile (7b): Beige crystals, yield (89 \%, 2.10 g); mp 238-240 ${ }^{\circ} \mathrm{C}$; IR $\left(\mathrm{cm}^{-1}\right)$ : 3387, 3350 and $3305\left(\mathrm{NH}\right.$ and $\left.\mathrm{NH}_{2}\right), 2185(\mathrm{CN})$ and $1646(\mathrm{CO})$; MS $\mathrm{m} / \mathrm{z}(\mathrm{M})^{+}=236 ;{ }^{1} \mathrm{H}-\mathrm{NMR}: \delta=4.73\left(\mathrm{~s}, 2 \mathrm{H}, \mathrm{NH}_{2}\right), 7.48(\mathrm{~d}, 2 \mathrm{H}, J=8.0 \mathrm{~Hz}$, arom-H), $7.53($ br s, $1 \mathrm{H}$, 
$\mathrm{NH}), 7.59\left(\mathrm{~d}, 2 \mathrm{H}, J=8.0 \mathrm{~Hz}\right.$, arom-H), $8.54\left(\mathrm{~s}, 1 \mathrm{H}, \mathrm{NH}_{2}\right), 9.97\left(\mathrm{~s}, 1 \mathrm{H}, \mathrm{NH}_{2}\right)$; Anal. calcd. for $\mathrm{C}_{10} \mathrm{H}_{9} \mathrm{ClN}_{4} \mathrm{O}$ : (236.66): C, 50.75; H, 3.83; N, 23.67. Found: C, 50.81; H, 3.92; N, 23.38.

(Z)-3-Amino-3-hydrazino-2-(2-thienylcarbonyl)-2-propenenitrile (7c): Beige crystals, yield (94\%, $1.95 \mathrm{~g})$; mp 175-177 ${ }^{\circ} \mathrm{C}$; IR ( $\left.\mathrm{cm}^{-1}\right)$ : 3449, 3331 and $3217\left(\mathrm{NH}\right.$ and $\left.\mathrm{NH}_{2}\right), 2189(\mathrm{CN})$ and $1659(\mathrm{CO})$; MS m/z $(\mathrm{M})^{+}=208 ;{ }^{1} \mathrm{H}-\mathrm{NMR}: \delta=4.72\left(\mathrm{~s}, 2 \mathrm{H}, \mathrm{NH}_{2}\right), 7.14(\mathrm{t}, 1 \mathrm{H}, J=4.0 \mathrm{~Hz}$, thienyl H-4), 7.55 (br s, $1 \mathrm{H}, \mathrm{NH}), 7.76(\mathrm{~d}, 1 \mathrm{H}, J=4.8 \mathrm{~Hz}$, thienyl H-3), $7.90(\mathrm{~d}, 1 \mathrm{H}, J=4.2 \mathrm{~Hz}$, thienyl H-2), $8.54(\mathrm{~s}, 1 \mathrm{H}$, $\mathrm{NH}_{2}$ ), 9.98 (s, 1H, $\mathrm{NH}_{2}$ ); Anal. calcd. for $\mathrm{C}_{8} \mathrm{H}_{8} \mathrm{~N}_{4} \mathrm{OS}$ : (208.24): C, 46.14; H, 3.87; N, 26.90; S, 15.40. Found: C, 45.89; H, 4.09; N, 26.59; S, 15.25.

\section{General procedure for the preparation of compounds 8a-c}

Each compound 7a-c $(10 \mathrm{mmol})$ was refluxed in dioxane $(20 \mathrm{~mL})$ for $30 \mathrm{~min}$. then left to cool at r.t. The target compounds separated as crystals that were collected by filtration and crystallized from the appropriate solvent.

3-Amino-5-phenyl-1H-4-pyrazolecarbonitrile (8a): Buff crystals from dioxane, yield (93 \%, $1.71 \mathrm{~g})$ mp 200-202 ${ }^{\circ} \mathrm{C}$; IR $\left(\mathrm{cm}^{-1}\right): 3348,3303\left(\mathrm{NH}_{2}\right), 3193(\mathrm{NH})$ and $2230(\mathrm{CN}) ; \mathrm{MS} \mathrm{m} / \mathrm{z}(\mathrm{M})^{+}=184 ;{ }^{1} \mathrm{H}-$ NMR: $\delta=6.50\left(\mathrm{~s}, 2 \mathrm{H}, \mathrm{NH}_{2}\right), 7.41-7.46(\mathrm{~m}, 3 \mathrm{H}$, arom. $\mathrm{H}), 7.80(\mathrm{~d}, 2 \mathrm{H}, J=7.2 \mathrm{~Hz}$, arom-H), 12.16 (br s, $1 \mathrm{H}, \mathrm{NH}$ ); Anal. calcd. for $\mathrm{C}_{10} \mathrm{H}_{8} \mathrm{~N}_{4}$ : (184.20): C, 65.21; H, 4.38; N, 30.42. Found: C, 65.03; H, 4.57; $\mathrm{N}, 30.12$.

3-Amino-5-(4-chlorophenyl)-1H-4-pyrazolecarbonitrile (8b): Brownish crystals from dioxane, yield (95\%, $2.07 \mathrm{~g})$; mp 218-220 ${ }^{\circ} \mathrm{C}$; IR $\left(\mathrm{cm}^{-1}\right): 3348,3302\left(\mathrm{NH}_{2}\right), 3137(\mathrm{NH})$ and $2223(\mathrm{CN})$; MS m/z (M) ${ }^{+}$ $=218 ;{ }^{1} \mathrm{H}-\mathrm{NMR}: \delta=6.40\left(\mathrm{~s}, 2 \mathrm{H}, \mathrm{NH}_{2}\right), 7.53(\mathrm{~d}, 2 \mathrm{H}, J=8.4 \mathrm{~Hz}$, arom-H), $7.80(\mathrm{~d}, 2 \mathrm{H}, J=8.4 \mathrm{~Hz}$, arom-H), 12.06 (br s, $1 \mathrm{H}, \mathrm{NH}$ ); Anal. calcd. for $\mathrm{C}_{10} \mathrm{H}_{7} \mathrm{ClN}_{4}$ : (218): C, 54.93; H, 3.23; N, 25.62. Found: C, 55.07; H, 3.46; N, 25.54.

3-Amino-5-(2-thienyl)-1H-4-pyrazolecarbonitrile (8c): Beige crystals from n-propanol, yield (93\%, $1.76 \mathrm{~g})$; $\mathrm{mp} 238-240{ }^{\circ} \mathrm{C}$; IR $\left(\mathrm{cm}^{-1}\right): 3325,3298\left(\mathrm{NH}_{2}\right), 3177(\mathrm{NH})$ and $2228(\mathrm{CN}) ; \mathrm{MS} \mathrm{m} / \mathrm{z}(\mathrm{M})^{+}=190$; ${ }^{1} \mathrm{H}-\mathrm{NMR}: \delta=6.38\left(\mathrm{~s}, 2 \mathrm{H}, \mathrm{NH}_{2}\right), 7.14(\mathrm{t}, 1 \mathrm{H}, J=4.4 \mathrm{~Hz}$, thienyl H-4), $7.70(\mathrm{~d}, 1 \mathrm{H}, J=4.4 \mathrm{~Hz}$, thienyl $\mathrm{H}-3), 7.93$ (d, $1 \mathrm{H}, J=4.2 \mathrm{~Hz}$, thienyl H-2), 12.00 (br s, $1 \mathrm{H}, \mathrm{NH})$; Anal. calcd. for $\mathrm{C}_{8} \mathrm{H}_{6} \mathrm{~N}_{4} \mathrm{~S}$ : (190.23): C, 50.51; H, 3.18; N, 29.45; S, 16.86. Found: C, 50.63; H, 3.02; N, 29.57; S, 17.02.

\section{Reaction of 8a-c with enaminone $\mathbf{2 c}$ and with enaminonitrile $\mathbf{9}$}

Procedure A: a mixture of each of compound 8a-c $(10 \mathrm{mmol})$ and each of $2 \mathrm{c}$ or 9 (10 mmol) was heated under reflux in $\mathrm{AcOH}(15 \mathrm{~mL})$ for $4 \mathrm{~h}$, during which time a precipitate is formed. The reaction mixture was filtered off and recrystallized from acetone.

Procedure B: a mixture of each of compound 8a-c $(10 \mathrm{mmol})$ and each of 2 c or 9 (10 mmol) was dissolved in ethanol $(2 \mathrm{~mL})$ in a small beaker. The reaction mixture was dried in air and the beaker was put in a domestic microwave oven $290 \mathrm{~W}$ and irradiate for $15 \mathrm{~min}$. The progress of the reaction was 
monitored every $3 \mathrm{~min}$. The product was extracted with acetone $(2 \times 10 \mathrm{~mL})$. The solvent was removed by distillation under reduced pressure to obtain the crude product that was further recrystallized from the appropriate solvent.

2-Phenyl-7-(2-thienyl)pyrazolo[1,5-a]pyrimidine-3-carbonitrile (12a): Yellow crystals from acetone, yield (89 \%, $2.68 \mathrm{~g})$; $\mathrm{mp} \mathrm{237-239}{ }^{\circ} \mathrm{C}$; IR $\left(\mathrm{cm}^{-1}\right): 2222(\mathrm{CN}) ; \mathrm{MS} \mathrm{m} / \mathrm{z}(\mathrm{M})^{+}=302 ;{ }^{1} \mathrm{H}-\mathrm{NMR}: \delta=7.45(\mathrm{t}$, $1 \mathrm{H}, J=4.2 \mathrm{~Hz}$, thienyl H-4), 7.62-7.70 (m, 3H, arom. H), 8.06 (d, 1H, J = 4.8 Hz, H-6), 8.20 (d, 2H, $J$ $=8.0 \mathrm{~Hz}$, arom. $\mathrm{H}), 8.24(\mathrm{~d}, 1 \mathrm{H}, J=4.2 \mathrm{~Hz}$, thienyl $\mathrm{H}-3), 8.63(\mathrm{~d}, 1 \mathrm{H}, J=4.2 \mathrm{~Hz}$, thienyl H-5), 8.82 (d, $1 \mathrm{H}, J=4.8 \mathrm{~Hz}, \mathrm{H}-5$ ); Anal. calcd. for $\mathrm{C}_{17} \mathrm{H}_{10} \mathrm{~N}_{4} \mathrm{~S}$ : (302.35): C, 67.53; H, 3.33; N, 18.53; $\mathrm{S}, 10.61$. Found: C, 67.64; H, 3.47; N, 18.47; S, 10.43 .

2-(4-Chlorophenyl)-7-(2-thienyl)pyrazolo[1,5-a]pyrimidine-3-carbonitrile (12b): Brownish red crystals from ethanol, yield $(86 \%, 2.88 \mathrm{~g}) ; \mathrm{mp} 252-254{ }^{\circ} \mathrm{C}$; IR $\left(\mathrm{cm}^{-1}\right): 2220(\mathrm{CN}) ; \mathrm{MS} \mathrm{m} / \mathrm{z}(\mathrm{M})^{+}=$ 336; ${ }^{1} \mathrm{H}-\mathrm{NMR}: \delta=7.36(\mathrm{t}, 1 \mathrm{H}, J=4.2 \mathrm{~Hz}$, thienyl H-4), 7.66 (d, 2H, $J=6.6 \mathrm{~Hz}$, arom. H), $7.99(\mathrm{~d}, 1 \mathrm{H}$, $J=4.8 \mathrm{~Hz}, \mathrm{H}-6), 8.12(\mathrm{~d}, 2 \mathrm{H}, J=6.6 \mathrm{~Hz}$, arom. H), $8.16(\mathrm{~d}, 1 \mathrm{H}, J=4.2 \mathrm{~Hz}$, thienyl H-3), $8.54(\mathrm{~d}, 1 \mathrm{H}$, $J=4.2 \mathrm{~Hz}$, thienyl H-5), 8.74 (d, $1 \mathrm{H}, J=4.8 \mathrm{~Hz}, \mathrm{H}-5$ ); Anal. calcd. for $\mathrm{C}_{17} \mathrm{H}_{9} \mathrm{ClN}_{4} \mathrm{~S}$ : (336.8): C, 60.62; H, 2.69; N, 16.64; S, 9.52. Found: C, 60.32; H, 3.07; N, 16.87; S, 9.64.

2,7-Di(2-thienyl)pyrazolo[1,5-a]pyrimidine-3-carbonitrile (12c): Beige crystals from acetone, yield $(88 \%, 2.71 \mathrm{~g}) ; \mathrm{mp} 251-253{ }^{\circ} \mathrm{C}$; IR $\left(\mathrm{cm}^{-1}\right): 2222(\mathrm{CN}) ; \mathrm{MS} \mathrm{m} / \mathrm{z}(\mathrm{M})^{+}=308 ;{ }^{1} \mathrm{H}-\mathrm{NMR}: \delta=7.34(\mathrm{t}, 1 \mathrm{H}$, $J=4.8 \mathrm{~Hz}$, thienyl H-4), $7.45(\mathrm{t}, 1 \mathrm{H}, J=4.8 \mathrm{~Hz}$, thienyl H-4), $7.91(\mathrm{~d}, 1 \mathrm{H}, J=4.8 \mathrm{~Hz}$, thienyl H-3), $7.96(\mathrm{~d}, 1 \mathrm{H}, J=4.8 \mathrm{~Hz}$, thienyl H-3), 8.03 (d, 1H, $J=5.2 \mathrm{~Hz}, \mathrm{H}-6), 8.25$ (d, 1H, $J=4.8 \mathrm{~Hz}$, thienyl H5), $8.60\left(\mathrm{~d}, 1 \mathrm{H}, J=4.8 \mathrm{~Hz}\right.$, thienyl H-5), $8.79(\mathrm{~d}, 1 \mathrm{H}, J=5.2 \mathrm{~Hz}, \mathrm{H}-5)$; Anal. calcd. for $\mathrm{C}_{15} \mathrm{H}_{8} \mathrm{~N}_{4} \mathrm{~S}_{2}$ : (308.38): C, 58.42; H, 2.61; N, 18.17; S, 20.80. Found: C, 58.12; H, 2.67; N, 18.09; S, 20.63.

2-Phenyl-5-(2-thienyl)pyrazolo[1,5-a]pyrimidine-3,6-dicarbonitrile (15a): Grey crystals from acetone, yield (88 \%, $2.87 \mathrm{~g})$; $\mathrm{mp} 291-293{ }^{\circ} \mathrm{C}$; IR $\left(\mathrm{cm}^{-1}\right): 2226(\mathrm{CN}) ; \mathrm{MS} \mathrm{m} / \mathrm{z}(\mathrm{M}){ }^{+}=327 ;{ }^{1} \mathrm{H}-\mathrm{NMR}: \delta=7.46(\mathrm{t}$, $1 \mathrm{H}, J=4.2 \mathrm{~Hz}$, thienyl $\mathrm{H}-4), 7.56-7.60(\mathrm{~m}, 3 \mathrm{H}$, arom. $\mathrm{H}), 8.12(\mathrm{~d}, 2 \mathrm{H}, J=8.2 \mathrm{~Hz}$, arom. H), 8.39 (d, $1 \mathrm{H}, J=4.2 \mathrm{~Hz}$, thienyl H-3), 8.67 (d, $1 \mathrm{H}, J=4.2 \mathrm{~Hz}$, thienyl H-5), 9.09 (s, 1H, H-7); Anal. calcd. for $\mathrm{C}_{17} \mathrm{H}_{10} \mathrm{~N}_{4} \mathrm{~S}$ : (327.36): C, 66.04; H, 2.77; N, 21.39; S, 9.79. Found: C, 66.25; H, 2.96; N, 21.17; S, 10.03 .

2-(4-Chlorophenyl)-5-(2-thienyl)pyrazolo[1,5-a]pyrimidine-3,6-dicarbonitrile (15b): Brown crystals from acetone, yield $(85 \%, 3.06 \mathrm{~g})$; $\mathrm{mp} 294-295{ }^{\circ} \mathrm{C}$; IR $\left(\mathrm{cm}^{-1}\right): 2230(\mathrm{CN})$; $\mathrm{MS} \mathrm{m} / \mathrm{z}(\mathrm{M}){ }^{+}=361 ;{ }^{1} \mathrm{H}-$ NMR: $\delta=7.46$ (t, $1 \mathrm{H}, J=4.2 \mathrm{~Hz}$, thienyl H-4), 7.67 (d, 2H, $J=8.2 \mathrm{~Hz}$, arom. H), 8.08 (d, 2H, $J=8.2$ $\mathrm{Hz}$, arom. H), 8.39 (d, $1 \mathrm{H}, J=4.2 \mathrm{~Hz}$, thienyl H-3), 8.65 (d, $1 \mathrm{H}, J=4.2 \mathrm{~Hz}$, thienyl H-5), 9.08 (s, $1 \mathrm{H}$, H-7); Anal. calcd. for $\mathrm{C}_{17} \mathrm{H}_{9} \mathrm{ClN}_{4} \mathrm{~S}$ : (361.81): C, 59.75; H, 2.23; N, 19.36; S, 8.86. Found: C, 59.46; H, 2.49 ; N, 19.19; S, 8.82.

2,5-Di(2-thienyl)pyrazolo[1,5-a]pyrimidine-3,6-dicarbonitrile 15c: Brown crystals from acetone, yield $(87 \%, 2.89 \mathrm{~g}) ; \mathrm{mp} 303-304{ }^{\circ} \mathrm{C}$; IR $\left(\mathrm{cm}^{-1}\right): 2227(\mathrm{CN}) ; \mathrm{MS} \mathrm{m} / \mathrm{z}(\mathrm{M})^{+}=333 ;{ }^{1} \mathrm{H}-\mathrm{NMR}: \delta=7.27(\mathrm{t}, 1 \mathrm{H}$, $J=4.8 \mathrm{~Hz}$, thienyl H-4), $7.45(\mathrm{t}, 1 \mathrm{H}, J=4.8 \mathrm{~Hz}$, thienyl H-4), $7.87(\mathrm{~d}, 1 \mathrm{H}, J=4.8 \mathrm{~Hz}$, thienyl H-3), 
$7.92(\mathrm{~d}, 1 \mathrm{H}, J=4.8 \mathrm{~Hz}$, thienyl H-3), $8.40(\mathrm{~d}, 1 \mathrm{H}, J=4.8 \mathrm{~Hz}$, thienyl H-5), 8.63 (d, $1 \mathrm{H}, J=4.8 \mathrm{~Hz}$, thienyl H-5), 9.06 (s, 1H, H-7); Anal. calcd. for $\mathrm{C}_{15} \mathrm{H}_{8} \mathrm{~N}_{4} \mathrm{~S}_{2:}$ (333.39): C, 57.64; H, 2.12; N, 21.01; S, 19.24. Found: C, 57.42; H, 2.43; N, 20.85; S, 19.57.

\section{Acknowledgements}

This research was done by the financial support of the Public Authority for Applied Education and Training (Transform grant TS-06-14) of Kuwait.

\section{References and Notes}

1. Chen, C.; Wilcoxen, K. M.; Huang, C. Q.; McCarthy, J. R.; Chen, T.; Grigoriadis, D. E. Optimization of 3-phenylpyrazolo[1,5-a]pyrimidines as potent corticotrophin-releasing factor-1 antagonists with adequate lipophilicity and water solubility. Bioorg. Med. Chem. Lett. 2004, 14, 3669-3673.

2. Wang, S. Q.; Fang, L.; Liu, X. J.; Zhao, K. Design, synthesis, and hypnotic activity of pyrazolo[1,5-a]pyrimidine derivatives. Chin. Chem. Lett. 2004, 15, 885-888.

3. Emelina, E. E.; Petrov, A. A.; Firsov, A. V. Aminoazoles in heterocycles synthesis: II. Trifluoromethyl-containing diketones in the synthesis of pyrazolo[1,5-a]pyrimidines. Russ. J. Org. Chem. 2001, 37, 852-858.

4. Bain, K. T. Management of chronic insomnia in elderly persons. Am. J. Geriatr. Pharmacother. 2006, 4, 168-192.

5. Dundar,Y.; Dodd, S.; Strobl, J.; Boland, A.; Dickson, R.; Walley, T. Comparative efficacy of newer hypnotic drugs for the short-term management of insomnia: a systematic review and metaanalysis. Hum. Psychopharmacol. 2004, 19, 305-322.

6. Noguchi, H.; Kitazumi, K.; Mori, M.; Shiba, T. Electroencephalographic properties of zaleplon, a non-benzodiazepine sedative/hypnotic, in rats. J. Pharmacol. Sci. 2004, 94, 246-251.

7. Ibrahim, N. S.; Abdelrazek, F. M.; Aziz, S. I.; Elnagdi, M. H.; Nitriles in organic synthesis: the reaction of trichloroacetonitrile with active methylene reagents. Monatsh. Chem. 1985, 116, 551556.

8. Al-Awadi, N. A.; Abdelkhalik, M. M.; Abdelhamid, I. A.; Elnagdi, M. H. Pyrolytic methods in organic synthesis: novel routes for the synthesis of 3-oxoalkanenitriles, 2-acyl anilines, and 2aroyl anilines. Synlett. 2007, 19, 2979-2982.

9. Tominaga, Y.; Matsuoka, Y.; Kohra, S.; Hosomi, A. A novel preparation of polarized ethylenes by the reaction of thioamides or dithiocarboxylates with tetracyanoethylene oxide. Synthesis of pyrazoles and pyrimidines. Heterocycles 1987, 26, 613-616.

10. Southwick, P. L.; Dhawan, B. Preparation of 4,6-diaminopyrazolo[3,4-d]pyrimidines with variations in substitutions at the 1- and 3-positions. J. Heterocycl. Chem. 1975, 12, 1199-1205.

11. Chritoforou, I. C.; Koutentis, P. A.; New regiospecific isothiazole C-C coupling chemistry Org. Biomol. Chem. 2006, 4, 3681-3693.

12. Al-Qalaf, F.; Abdelkhalik, M. M.; Al-Enzy, A.; Al-Agamy, G. Studies with functionally substituted enamines: synthesis of 2-aroyl-3-dimethylamino-2-propenenitrile and their reactivity toward nitrogen nucleophiles. Heterocycles 2008, 75, 145-156. 
13. Elnagdi, M. H.; Elmoghayar, M. R. H.; Elgemeie, G. E. H. Chemistry of pyrazolopyrimidines. In Advances in Heterocyclic Chemistry; Katritzky, A. R., Ed.; Academic Press Inc.: New York, USA, 1987; Vol. 41, pp. 319-376.

14. Maquestiau, A.; Target, H.; Van Den Eyden, J. J. Preparation and characterization of pyrazolo[1,5-a] pyrimidines. Bull. Soc. Chim. Belg. 1992, 101, 131-136.

15. Gavrin, L.; Lee, A.; Provencher, B. A.; Massefski, W. W; Huhn, S. D; Ciszewski, G. M.; Cole, D. C; McKew, J. C. Synthesis of pyrazolo[1,5- $\alpha$ pyrimidinone regioisomers. J. Org. Chem. 2007, 72, 1043-1046.

16. Anwar, H. F.; Fleita, D. H.; Kolshorn, H.; Meier, H.; Elnagdi, M. H. 2H-Pyrazol-3-ylamines as precursors for the synthesis of polyfunctionally substituted pyrazolo[1,5-a]pyrimidines. Arkivoc 2006, $(x v), 133-141$.

17. Emelina, E. E.; Petrov, A. A.; Firsov, A.V. $\alpha$-Aminoazoles in syntheses of heterocycles: 3(5)aminopyrazole-4-carbonitriles in the synthesis of pyrazolo[1,5-a]pyrimidines. Russ. J. Org. Chem. 2007, 43, 471-473.

18. Michael, D.; Mingos, P.; Baghurst, D. R. Microwaves in chemical synthesis. In The New Chemistry, $3^{\text {rd }}$ Ed.; Hall, N., Ed.; Cambridge University Press: Cambridge, MA, USA, 2000; Chapter 4, pp. 67-75.

19. Hájek, M.; Microwave activation of catalytic reactions. In Microwaves in Organic Synthesis; Loupy, A., Ed.; WILEY-VCH Verlag GmbH \& Co: Weinheim, Germany, 2006; Vol. 2, Chapter 13, pp. 634-637.

Sample Availability: Samples of the compounds 8a-c, 12a-c and 15a-c are available from authors.

(C) 2009 by the authors; licensee Molecular Diversity Preservation International, Basel, Switzerland. This article is an open-access article distributed under the terms and conditions of the Creative Commons Attribution license (http://creativecommons.org/licenses/by/3.0/). 